BIOMEDICAL AND BIOSOCIAL ANTHROPOLOGY
$\begin{gathered}\text { Official Journal of the International Academy } \\ \text { of Integrative Anthropology } \\ \text { journal homepage: http://bba-journal.com }\end{gathered}$

In-depth investigation of analgesic activity of N-(4-methoxybenzyl)4-methyl-2.2-dioxo-1 $\mathrm{H}-2 \lambda^{6} .1$-benzothiazine-3-carboxamide derivate on different models of pain perception

\title{
Malchenko O. V.
}

National Pirogov Memorial Medical University, Vinnytsya, Ukraine

\section{ARTICLE INFO}

Received: 26 January 2021

Accepted: 26 February 2021

UDC: $615.211: 599.323 .4$

\section{CORRESPONDING AUTHOR}

e-mail: malchenko2576@gmail.com Malchenko O. V.

\begin{abstract}
Among N-(4-methoxybenzyl)-4-methyl-2.2-dioxo-1H-2 $\lambda^{6} .1$-benzothiazine-3carboxamide derivates, the compound methoxybenzyl-amide derivative 4-methyl-2.2dioxo-1H-2 $\lambda^{6}$.1-benzothiazine-3-carboxylic acid (compound NI-9) with pronounced analgesic and anti-inflammatory activities, which was superior to those of diclofenac and lornoxicam in the model of carrageenan edema. The aim of the study was to investigate the analgesic effect of benzothiazine-3-carboxamide derivative on different models of somatic and neuropathic pain syndromes. The study was performed on 91 male Wistar rats. Compound NI-9 and reference drugs meloxicam, diclofenac and gabapentin were administered intragastrically at doses of 3, 5, 8 and $5 \mathrm{mg} / \mathrm{kg}$, respectively, corresponding to their ED50 in analgesic activity. Acetic spasms in mice, a model of thermal irritation of the tail flick in rats, as well as adjuvant arthritis and diabetic polyneuropathy were selected as models of pain syndromes. The results were processed in the program STATISTICA 10.0 using non-parametric methods. The results showed that methoxybenzyl-amide derivative 4-methyl-2.2-dioxo-1H-2 $\lambda^{6} .1$ benzothiazine-3-carboxylic acid (compound NI-9) has a pronounced analgesic effect on various models of pain syndromes, both somatic and inflammatory. and of neurogenic origin. The analgesic activity of the compound NI-9 in the model of acetic acid cramps in mice and thermal irritation in rats was 38.09 and $49.75 \%$, respectively, which was higher than that of meloxicam (36.73 and $45.68 \%$ ), and inferior to diclofenac (41.95 and $55.95 \%$ ). In the model of the systemic inflammatory process (adjuvant arthritis), the analgesic effect of NI-9 was statistically superior to meloxicam and diclofenac (43.32\% vs. 26.26 and $33.69 \%$ ). In a model of neuropathic pain syndrome (diabetic neuropathy), the analgesic effect of methoxybenzyl-amide derivative 4-methyl-2.2-dioxo$1 \mathrm{H}-2 \lambda^{6} .1$-benzothiazine-3-carboxylic acid was greater than meloxicam (18.96 vs. $13.34 \%)$, but this figure was lower than that of gaapentin (20.83\%). Further in-depth study of its pharmacodynamics and toxicity will be the theoretical basis for the development on the basis of this biologically active compound of the original drug with analgesic and anti-inflammatory activities.

Keywords: $N$-(4-methoxybenzyl)-4-methyl-2.2-dioxo-1H-2 $2 \Lambda^{6} .1$-benzothiazine-3carboxamide, analgesic effect, acetic-acid-induced writhing test, tail-flick test, adjuvant arthritis, diabetic neuropathy, rats.
\end{abstract}

\section{Introduction}

Pain is not only a symptom of most diseases, but is a complex psychophysiological phenomenon, which involves the mechanisms of regulation and formation of emotions, motor, humoral and hemodynamic manifestations that form the pain syndrome $[6,11,13]$. According to the International Association of Pain Study (IAPS), "Pain is an unpleasant sensory and emotional experience that is associated with existing or possible tissue damage or as described in terms of such damage" [16]. Chronic pain is the greatest threat to health and quality of life. It has no protective function and has no biological expediency. On the contrary, chronic pain leads to maladaptation, to the abnormal perception of pain and pain impulses and is accompanied by various CNS disorders [1].

The above explains the constant interest of scientists in the pharmacological correction of pain. The general 
aging of the world's population, the negative impact of environmental and other factors leads to an increase in the number of diseases that are accompanied by pain and inflammation. Although mortality rates are highest for cardiac infarction and stroke, infectious diseases, cancers, and diabetes, chronic pain is a leading source of human suffering and disability $[7,20]$.

The class of benzothiazine-3-carboxamides is promising for the creation of new highly effective and safe analgesics. According to the results of primary pharmacological screening from a large group of $\mathrm{N}$ hetaryl(aryl)alkyl-substituted 4-methyl-2.2-dioxo-1 $\mathrm{H}-2 \lambda^{6} .1$ benzothiazine-3-carboxamides, their close structural analogues and some polymorphic modifications, the most active compounds were identified, namely $\mathrm{N}$-thiophen-2ylmethyl- and N-4-methoxybenzyl-amides of 4-methyl-2.2dioxo-1H-2 $\lambda^{6} .1$-benzothiazine-3-carboxylic acid, which after oral administration at a dose of $20 \mathrm{mg} / \mathrm{kg}$ showed pronounced analgesic and anti-inflammatory activity in a model of carrageenan edema in rats, the degree of which was superior to diclofenac and lornoxicam [17, 19]. It was expedient to study them as drugs with analgesic and antiinflammatory action. However, the acute toxicity of these compounds revealed that the substance $\mathrm{N}-4$ methoxybenzyl-amides of 4-methyl-2.2-dioxo-1 H-2 $2 \lambda^{6} .1$ benzothiazine-3-carboxylic acid (compound with laboratory code NI-9) proved to be safer, which was chosen as the lead compound.

The aim of the study was to investigate the analgesic effect of N-4-methoxybenzyl-amides of 4-methyl-2.2-dioxo$1 \mathrm{H}-2 \lambda^{6}$.1-benzothiazine-3-carboxylic acid on various models of somatic and neuropathic pain syndromes.

\section{Materials and methods}

The experiments were performed on 91 adult male Wistar rats and 40 white nonlinear adult mice of both sexes obtained from the vivarium of the Institute of Pharmacology and Toxicology of the National Academy of Medical Sciences of Ukraine. During the experiment, the animals were in the vivarium of National Pirogov Memorial Medical University, Vinnytsya on a standard diet with access to water ad libitum with 12-hour lighting (day/night). The research was conducted in accordance with the general ethical principles of animal experiments regulated by the provisions of the "European Convention for the Protection of Vertebrate Animals Used for Experimental and Other Scientific Purposes" (Strasbourg, 1986, as amended, 1998) and the Law of Ukraine № 3447-IV of 21.02.2006, as amended "On the protection of animals from cruel treatment". Identification of animals was performed using a system of individual color markings on the body, the studies took into account seasonal and circadian rhythms of animals.

An "acetic-acid-induced writhing" model in mice was used to assess peritovisceral pain sensitivity. Recorded the number of "writhings" that occurred within 20 minutes after intra-abdominal injection of $0.6 \%$ acetic acid solution
( $1 \mathrm{ml}$ per $100 \mathrm{~g}$ of animal weight). The test substance (compound $\mathrm{NI}-9$ ) and reference drugs (meloxicam and diclofenac) were administered once $\mathrm{i} / \mathrm{g}$ for 40 minutes to the action of acetic acid in their conditionally effective analgesic dose (ED50), which was determined in previous experiments or borrowed from the literature and was 3, 5 and $8 \mathrm{mg} / \mathrm{kg}$, respectively. The control group of animals received equivolume amounts of solvents. The analgesic effect was assessed by the indicator (in \%) of the reduction in the number of cramps in the study group relative to control $[10,14]$.

To assess thermal somatic pain, a rat tail-flick stimulation test using a Tail flick analgesia meter Ugo Basile (Italy) was used. Evaluated the latency of pulling the tail from the beam source, expressed in seconds. Animals were randomized relative to baseline latency, and the experiment included rats ranging from 4 to $12 \mathrm{~s}$. The severity of the antinociceptive effect was assessed by increasing the duration of the latent period. At increase of LP more than $25 \mathrm{~s}$ with the further research was stopped for the prevention of a thermal burn of an animal. Test substances and reference drugs were administered as in the previous experiment.

Pain sensitivity in chronic inflammation was determined in adjuvant arthritis in rats, which was simulated by the introduction of $0.1 \mathrm{ml}$ of complete Freund's adjuvant (Thermo Fisher scientific, USA) under the plantar aponeurosis of the hind right paw [14]. The introduction of drugs began on day 14 (the peak of autoimmune inflammation). The studies were performed on days 14 and 28 after adjuvant inoculation. Animals were divided into 4 groups ( 7 animals each), the first group - relatively healthy rats (positive control), the second group - animals with adjuvant arthritis without treatment (negative control). The third and fourth groups included animals which, against the background of the development of adjuvant arthritis, were injected intragastrically (i/g) separately with the test compound and the reference drug. Animals in the control group received an equivolume amount of solvent under similar regimens and routes of administration. The degree of nociception and analgesic effect of the compounds was determined using a dolorimeter (Dolorimeter Baseline, USA) by assessing the threshold of pain sensitivity - the minimum pressure on the lower surface of the rat foot $\left(\mathrm{g} / \mathrm{mm}^{2}\right)$, which caused pain in animals (vocalization and/or paw pulling). We compared the threshold of pain sensitivity in the right limb before the study (baseline), as well as on the 14th and 28th day, respectively.

Simulations of neuropathic pain were replicated in a model of diabetic polyneuropathy in rats, which developed on the background of diabetes mellitus caused by a single intraperitoneal injection of streptozotocin (Sigma, USA) at a dose of $60 \mathrm{mg} / \mathrm{kg}$. Animals were divided into the following groups: group 1 - diabetes mellitus without treatment (negative control); animals of groups 2, 3 and 4 on the 
background of the development of diabetes at the end of the 6th week were administered a single compound NI-9, meloxicam and gabapentin, respectively. Evaluated the appearance of animals, changes in food and water behavior. Animal survival was recorded throughout the study period. Before the experiment, as well as every 7 days, the body weight, blood glucose level (using a portable glucometer and test strips), and pain perception were determined using a dolorimeter (Dolorimeter Baseline, USA) by determining the threshold of pain sensitivity - minimal pressure on the upper surface of the rat's foot $(\mathrm{g} / \mathrm{mm} 2)$, which caused a painful reaction in the animal (vocalization and/or pulling of the paw). In addition, the condition of the damaged extremities (damage to the nails and phalanges of the fingers) was visually determined.

Statistical processing of the obtained results was performed using computer programs by methods of variation statistics in the program STATISTICA 10.0 using non-parametric methods.

\section{Results}

The results showed that the introduction of acetic acid solution control group rats caused a painful reaction, which manifested itself in the form of spastic contractions of the abdominal muscles in the amount of $44.10 \pm 3.48$. Against the background of administration of carboxamide derivative (NI-9) to rats, a statistically significant decrease in the number of cramps was observed in 20 minutes after irritation of the peritoneum with acetic acid by $38.09 \%$, which indicated the presence of analgesic action. The reference drugs meloxicam and diclofenac also reduced the number of flexor muscle contractions in mice by 36.73 and $41.95 \%$, respectively, but this did not have a statistically significant difference with the compound studied (Fig. 1).

The effect of the compound NI-9, meloxicam and diclofenac on the dynamics of the latent period of pulling the tail of rats in the test "tail-flick" (Fig. 2) showed that the compound NI-9 showed a statistically significant analgesic

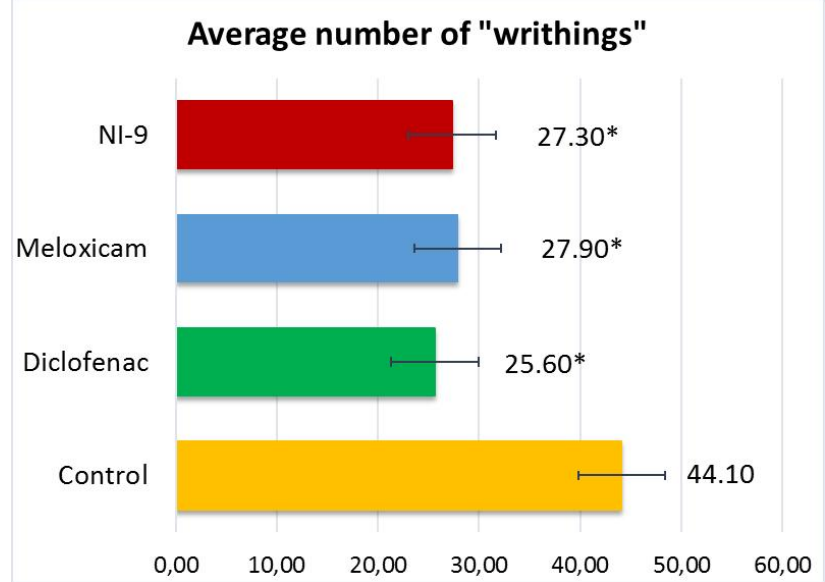

Fig. 1. Analgesic effect of $\mathrm{NI}-9$, diclofenac and meloxicam in a model of acetic acid cramps in mice $(n=10)$. * - statistically significant reduction in the number of cramps relative to control.

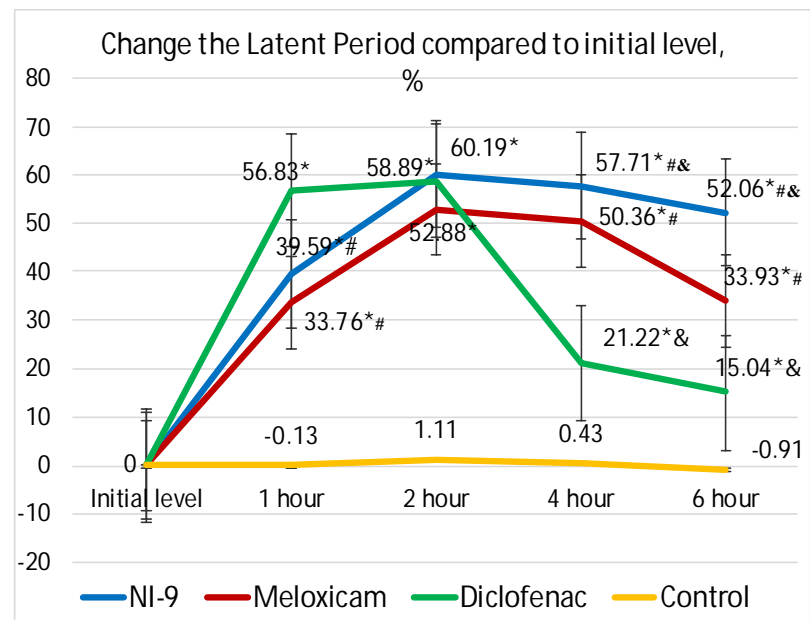

Fig. 2. Analgesic effect of NI-9 and reference drugs in a model of tail-flick thermal stimulation in rats $(n=7) .{ }^{*}$ - statistically significant differences in control $(p<0.05)$; \# - statistically significant differences relative to diclofenac $(p<0.05)$; \& - statistically significant differences with respect to meloxicam $(p<0.05)$.

effect from 1 hour, which reached a maximum at 2-1 hour after administration, lasted almost unchanged until the 4th hour, and then gradually decreased, but at the 6th hour was still quite pronounced. The most chemically similar drug meloxicam was inferior in analgesia, especially in the later stages of the study. The reference representative of nonsteroidal anti-inflammatory drugs - diclofenac - in the 1st hour of the study statistically outperformed both drugs in terms of analgesic effect, in the 2nd hour - was equal to them, but at 4 and 6 hours its antinociceptive effect decreased significantly, and reached, respectively, 21.22 and $15.04 \%$ relative to the initial level.

The next step was to study the analgesic effect of $\mathrm{NI}-9$, meloxicam and diclofenac in a model of systemic inflammation - adjuvant arthritis in rats. It was found that the introduction of Freund's adjuvant causes an inflammatory process, which is accompanied by macroscopic, hematological and other changes in the body of rats, including inflammatory hyperalgesia, as evidenced by a statistically significant decrease in the threshold of pain sensitivity by 14 days. Subsequently, in animals with adjuvant arthritis without treatment, the threshold of pain sensitivity increased slightly, but at 28 days still remained much lower than the initial level (Fig. 3). Treatment of rats with NI-9, like meloxicam and diclofenac, significantly reduced the manifestations of hyperalgesia and other signs of inflammatory response, as evidenced by a statistically significant increase in the threshold of pain sensitivity in all three groups. The most powerful analgesic effect was shown by the carboxamide derivative.

The ability of NI-9 to affect neuropathic pain was further evaluated. A model of diabetic polyneuropathy was chosen for this purpose. It was found that a single injection of streptozotocin at a dose of $60 \mathrm{mg} / \mathrm{kg}$ caused the development of experimental diabetes mellitus. During the 


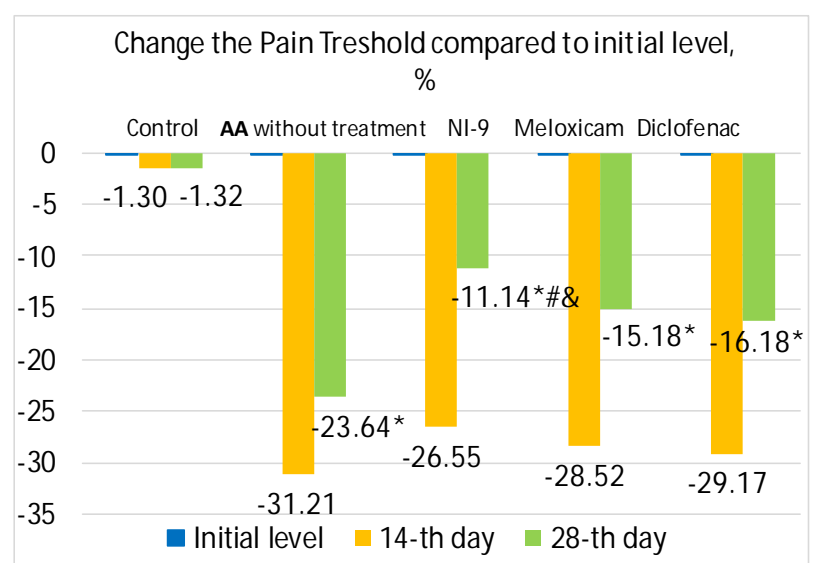

Fig. 3. Analgesic effect of $\mathrm{NI}-9$ and reference drugs in the model of adjuvant arthritis in rats $(n=7)$. ${ }^{*}$ - statistically significant differences $(p<0.05)$ relative to 14 days in the corresponding group; \# - statistically significant differences $(p<0.05)$ relative to diclofenac; $\&$ - statistically significant differences $(p<0.05)$ relative to meloxicam.

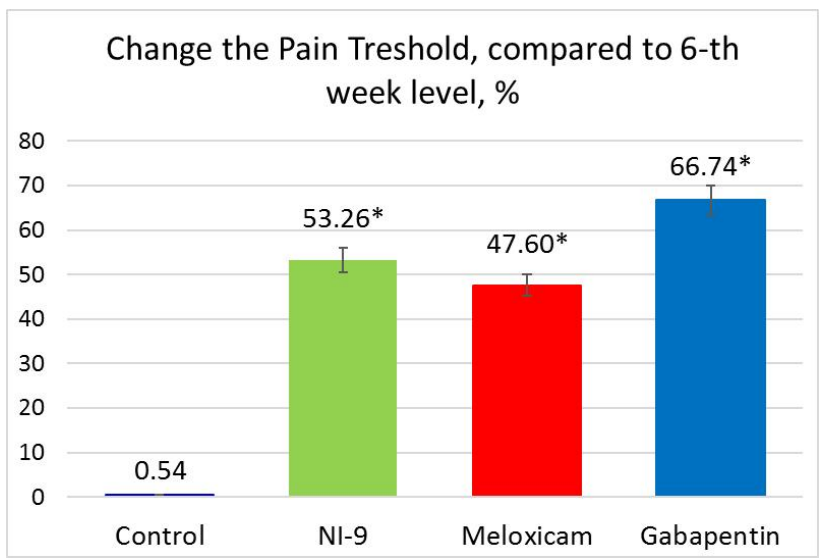

Fig. 4. Analgesic activity of NI-9, meloxicam and gabapentin with their single intraperitoneal administration in rats with diabetic neuropathy. * - statistically significant differences $(p<0.05)$ relative to the 6 th week in the respective group.

entire observation period ( 6 weeks) the animals consumed significantly more water (polydipsia), significantly increased urination (polyuria), the animals became lethargic, poorly consumed food, lost weight. There have been cases of death of animals.

The development of experimental diabetes caused changes in the threshold of pain sensitivity in rats. Statistically significant changes in the threshold of pain sensitivity were registered on the 7 th day after the introduction of streptozotocin, which continued to decrease throughout the observation period, and at the 6th week decreased by $69.5 \%$ relative to baseline. In addition, the animals developed external signs of polyneuropathy, which were manifested by changes in the nails of animals, interphalangeal joints and metatarsals. At the end of the 6 th week, the animals were given the initial value of the pain sensitivity threshold, after which the rats of the experimental groups were administered the compound $\mathrm{NI}-9$ and reference drugs, and the control group - the solvent. Evaluation of the therapeutic effect of the compound NI-9 showed that 2 hours after its introduction (peak of analgesic activity) the threshold of pain sensitivity increased by $31.14 \%$ compared to before the introduction, while the reference drug meloxicam increased this figure by only $26.0 \%$, and gabapentin contributed to the growth of this indicator by an average of only $35.16 \%$ (Fig. 4).

\section{Discussion}

Among the drugs used to treat pain syndromes (socalled "pain killers"), the group of nonsteroidal antiinflammatory drugs occupies a leading position, surpassing the frequency of use of opioids and even paracetamol. Their effectiveness is due to the multicomponent mechanism of action, which includes the antiprostaglandin component, as well as a number of other effects (antioxidant, antibradykinin, effects on the system of nitrogen monoxide, hydrogen sulfide, ion channels, etc.). The set of positive pharmacological effects (analgesic, antiinflammatory, antipyretic and others) are combined in this group of drugs with antiplatelet action, the ability to prevent oncological diseases, etc. These drugs have many different dosage forms that make them convenient to use, a moderate number of side effects, attractive pharmacoeconomic profile.

An important and expedient direction in the creation of highly effective analgesics is the modification of molecules of already known drugs by bioisosteric replacement of substituents, which can significantly increase the effectiveness and safety of new biologically active compounds [17, 18].

The International Association for the Study of Pain, depending on the mechanism underlying the development of this pathological syndrome, divides it into three main groups: somatogenous (nociceptive), neurogenic and psychogenic [12]. Somatogenous pain syndrome occurs due to activation of nociceptors in trauma, inflammation, tissue ischemia. Neurogenic pain occurs when the central nervous system (central) or peripheral nerve impulses (neuropathic pain) are disturbed. If the pain does not have a clear physiological cause, it is considered psychogenic. Depending on the location of the injury, somatic pain is divided into: superficial (damage to the skin), deep (damage to the musculoskeletal system) and visceral (with damage to internal organs). According to the literature, it is known [2] that various analgesics (nonsteroidal antiinflammatory drugs, opioids) are effective in the treatment of somatogenous pain and show relatively low activity against neuropathic pain and in particular allodynia. Analysis of the literature [22] showed that the cause of this dependence may be the presence of cyclooxygenase- 1 in the spinal cord of rats, which is activated in various models of nerve pain in trauma (ligation or cutting of peripheral nerves) and inflammation. In addition, the main mechanism for the development of hyperalgesia in neuropathic pain is 
Table 1. Analgesic activity of NI-9 and reference drugs in different models of pain sensitivity (\%).

\begin{tabular}{|l|c|c|c|c|}
\hline \multicolumn{1}{|c|}{ Compound } & "acetic-acid-induced writhing" model & $\begin{array}{c}\text { "tail-flick" model } \\
\text { in mice }\end{array}$ & $\begin{array}{c}\text { Adjuvant arthritis } \\
\text { in rats }\end{array}$ & $\begin{array}{c}\text { Diabetic neuropathy } \\
\text { in rats }\end{array}$ \\
\hline NI-9 & 38.09 & 49.75 & 43.32 \\
\hline Meloxicam & 36.73 & 45.68 & 26.26 \\
\hline Diclofenac & 41.95 & 55.92 & 33.69 \\
\hline Gabapentin & - & - & - & 13.34 \\
\hline
\end{tabular}

a violation of GABA- and glycine-ergic inhibition of nociceptive neurons in the dorsal horns of the spinal cord with a simultaneous increase in NMDA-mediated excitation [5]. The experiment showed [4] that such factors of the immune system as cytokines (interleukin (IL) $-1 \beta$, IL-6, tumor necrotic factor (TNF- $\alpha$ ) and cells (neutrophils, macrophages, T-lymphocytes, etc.) are important mediators in the development of pain syndromes in such conditions.

The results presented in this work showed that the methoxybenzyl-amide derivative 4-methyl-2.2-dioxo-1 $\mathrm{H}$ $2 \lambda^{6} .1$-benzothiazine-3-carboxylic acid (compound NI-9) has a pronounced antinociceptive effect in all models of pain syndromes. Table 1 summarizes the data on the analgesic activity of said compound.

It can be noted that in the models of somatic and thermal damage the activity of this compound is compared with meloxicam, tends to some advantage over its effect, but is inferior to the "gold standard of NSAIDs" - diclofenac. At the same time, in the model of the experimental inflammatory process (adjuvant arthritis), the compound NI-9 showed a stronger antinociceptive effect than both reference drugs. In addition, in the model of diabetic polyneuropathy, the study compound was also superior to meloxicam, but inferior to gabapentin, which is known to be the major agent in the treatment of neuropathic pain. We believe that the results obtained may be the result of greater selectivity of

\section{References}

[1] Atkinson, T. J., \& Fudin, J. (2020). Nonsteroidal Antiinflammatory Drugs for Acute and Chronic Pain. Phys Med \& Rehabil Clin, 31(2), 219-231. doi: 0.1016/j.pmr.2020.01.002

[2] Banos, J. E., Sanchez, G., Berrendero, F., \& Maldonado, R. (2003). Neuropathic pain: some clues for future drug treatments. Mini Rev Med Chem, 3, 719-727. doi: 10.2174/ 1389557033487773

[3] Burukoglu, D., Baycu, C., Taplamacioglu, F., Sahin, E., \& Bektur, E. (2016). Effects of nonsteroidal anti-inflammatory meloxicam on stomach, kidney, and liver of rats. Toxicol Ind Health, 32(6), 980-986. doi: $10.1177 / 0748233714538484$

[4] Calvo, M., Dawes, J. M., \& Bennett, D. L. (2012). The role of the immune system in the generation of neuropathic pain. Lancet Neurol, 11(7), 629-642. doi: 10.1016/S1474-4422(12)701345

[5] Campbell, J., \& Meyer, R. (2006). Mechanisms of neuropathic pain. Neuron, 52(1), 77-92. doi: 10.1016/j.neuron.2006.09.021

[6] Clarke, T. C., Nahin, R. L., Barnes, P. M., \& Stussman, B. J. (2016). Use of Complementary Health Approaches for Musculoskeletal Pain Disorders Among Adults: United States, 2012. Natl Health Stat Report, 98, 1-12.

[7] Henschke, N., Kamper S. J., \& Maher C. G. (2015). The this molecule to COX-2, the activation of which occurs under conditions of inflammation and participates in the development of pain response of neuropathic origin [15, 21]. In addition, alpha-1 and alpha-2 adrenoreceptors, dopamine receptors, and partially NMDA receptors are involved in the mechanisms of antinociceptive action of NI-9 compounds [8]. There is also a stronger effect of this compound on the system of nitrogen monoxide, as well as a stimulating effect on hydrogen sulfide metabolism, which not only promotes anti-inflammatory and analgesic activity, but also explains its greater safety against the stomach $[3,9]$.

\section{Conclusion}

The data obtained indicate that methoxybenzyl-amide derivative of 4-methyl-2.2-dioxo- $1 \mathrm{H}-2 \lambda^{6}$. 1 -benzothiazine-3carboxylic acid (compound NI-9) has a pronounced analgesic effect on various models of pain syndromes, both somatic and inflammatory and neurogenic origin. In terms of analgesic effect, this compound is superior to meloxicam in all models of pain syndromes, and diclofenac in the model of experimental inflammation (adjuvant arthritis). Further in-depth study of its pharmacodynamics and toxicity will be the theoretical foundation for the development on the basis of this biologically active compound of the original drug with analgesic and antiinflammatory activities.

epidemiology and economic consequences of pain. Mayo Clinic Proceedings, 90(1), 139-147. doi: 10.1016/ j.mayocp.2014.09.010

[8] Malchenko, O. V., Voloshchuk, N. I. \& Hrymalovska, O. V. (2021). Експериментальне дослідження механізмів аналгезуючої дії похідного 4-метил-2,2-діксо-1Н-2 $\lambda^{6}, 1$-бензотіазин-3карбонової кислоти (сполука NI-9) у щурів [Experimental study of analgesic mechanisms of 4-methyl-2,2-dioxo- $1 \mathrm{H}$ 2?6,1-benzothiazine-3-carboxylic acid derivative (compound NI-9) in rat]. Вісник Вінницького національного медичного університету - Reports of Vinnytsia National Medical University, 1(25), 12-17. doi: 10.31393/reports-vnmedical2021-25(1)-02

[9] Malchenko, O. V., Voloshchuk, N. I. \& Pentiuk, N. O. (2020). Investigation of 4-methyl-2.2-dioxo- $1 \mathrm{H}-2 \lambda^{6}, 1$-benzothiazine3-carboxamide derivative influence on the biochemical markers of gastric mucosa in rats. Biomedical and Biosocial Anthropology, 41, 36-40. doi: 10.31393/bba41-2020-06

[10] Mironov, A. N. (red). (2012). Руководство по проведению доклинических исследований лекарственных средств. Часть первая [Guidelines for conducting preclinical studies of drugs. Part one]. М.: Гриф и К - М.: Grif and К. 
[11] Morgan, B., \& Wooden, S. (2018). Diagnosis and treatment of common pain syndromes and disorders. Nurs. Clin. North. Am, 53(3), 349-360. doi: 10.1016/j.cnur.2018.04.004

[12] Nicholas, M., Vlaeyen, J., Rief, W., Barke, A., Aziz, Q., Benoliel, R. ... \& Treede, R. D. (2019). The IASP classification of chronic pain for ICD-11: chronic primary pain. PAIN, 160(1), 28-37. doi: 10.1097/j.pain.0000000000001390

[13] Palmer, G. M. (2016). Pain management in the acute care setting: Update and debates. J Paediatr Child Health, 52(2), 213-220. doi: 10.1111/jpc. 13134

[14] Stefanov, O. V. (red). (2001). Доклінічні дослідження лікарських засобів: Метод. рекомендації [Preclinical studies of drugs: Method. Recommendations]. K.: VD "Avitsena".

[15] Takeda, K., Sawamura, S., Tamai, H., Sekiyama, H., \& Hanaoka, K. (2005). Role for Cyclooxygenase 2 in the Development and Maintenance of Neuropathic Pain and Spinal Glial Activation. Anesthesiology, 103, 837-844.

[16] Treede, R. D., Rief, W., Barke, A., Aziz, Q., Bennett, M. I., Benoliel, R. ... \& Wang, S. J. (2019). Chronic pain as a symptom or a disease: the IASP Classification of Chronic Pain for the International Classification of Diseases (ICD-11). PAIN, 160(1), 19-27. doi: 10.1097/j.pain.0000000000001384

[17] Ukrainets, I. V., Hamza, G. M., Burian, A. A., Voloshchuk, N. I., Malchenko, O. V., Shishkina, S. V. ... \& Sim, G. (2018). Molecular Conformations and Biological Activity of N-Hetaryl(aryl)alkyl4-methyl-2,2-dioxo-1H-2 $\lambda^{6}, 1$-benzothiazine-3-carboxamides.
Sci Pharm, 86(4), 50. doi: 10.3390/scipharm86040050

[18] Ukrainets, I. V., Mospanova, E. V., Savchenkova, L. V., \& Yankovich, S. I. (2011). 4-Hydroxy-2-quinolones. 195. Synthesis of novel, potential analgesics based on 4(hetarylmethyl)amino-2-oxo-1,2-dihydroquinoline-3-carboxylic acids. Chem Heterocycl Compd, 47(1), 67-73. doi: 10.1007/ s10593-011-0721-4

[19] Ukrainets, I. V., Petrushova, L. A., Fedosov, A. I., Voloshchuk, N. I., Bondarenko, P. S., Shishkina, S. V., ... \& Sim, G. (2020). Crystal Habits and Biological Properties of $\mathrm{N}-(4-$ Trifluoromethylphenyl)-4-Hydroxy-2, 2-Dioxo-1H-2 $\lambda^{6}, 1$ Benzothiazine-3-Carboxamide. Scientia Pharmaceutica, 88(1), 45-60. doi: 10.3390/scipharm88010001

[20] Wager, J., Brown, D., Kupitz, A., Rosenthal, N., \& Zernikow, B. (2020). Prevalence and associated psychosocial and health factors of chronic pain in adolescents: differences by sex and age. European Journal of Pain, 24(4), 761-772. doi: 10.1002/ejp.1526

[21] Yongwoo, J., Minseok, K., \& Sun Wook, H. (2020). Molecular mechanisms underlying the actions of arachidonic acid-derived prostaglandins on peripheral nociception. $J$ Neuroinflammation, 17, 30. doi: 10.1186/s12974-020-1703-1

[22] Zhu, X., \& Eisenach, J. C. (2003). Cyclooxygenase-1 in the spinal cord is altered after peripheral nerve injury. Anesthesiology, 99, 1175-1179. doi: 10.1097/00000542200311000-00026 